\title{
Maternal outcome in relation to Biochemical parameters in Hypertensive disorders in Pregnancy
}

\author{
Andrews $\mathrm{L}^{1}$, Mehta $\mathrm{L}^{2}$, Sharma $\mathrm{A}^{3}$, Haridas $\mathrm{N}^{4}$, Vaishnav $\mathrm{S}^{5}$, Jadav $\mathrm{P}^{6}$ \\ Associate professor, Dept of Biochemistry, GMERS Medical College,Dharpur-Patan, Gujarat, \\ Assistant professor, Dept of Obstetrics \& Gynaecology, GMERS Medical College, Gandhinagar, Gujarat. \\ Associate professor, Dept of Obstetrics \& Gynaecology, GMERS Medical College, Dharpur-Patan, Gujarat \\ Prof \& Head, Dept of Biochemistry, PS Medical College, Shree Krishna Hospital, Karamsad, Gujarat \\ Professor, Dept of Obstetrics \& Gynecology, PS Medical College, Shree Krishna Hospital, Karamsad, Gujarat \\ Assistant professor, Dept of Community Medicine, GMERS Medical College, Gandhinagar, Gujarat
}

Abstract: The aim of the present study was to correlate biochemical parameters like serum uric acid, LDH, $A S T$, ALT, prothrombin time and APTT with maternal outcomes in Hypertensive diseases in pregnancy. Out of the 328 PIH cases, 9 (2.74\%) maternal deaths were recorded during this study and 166 mothers were having complications and 194 mothers were having preterm delivery. All the 9 maternal death cases were admitted during emergency, $8(88.8 \%)$ came from rural areas, belonged to low socioeconomic class and had not taken antenatal care, 7 were primigravidas and from the 20-25 years age group. Serum levels of uric acid, LDH, AST, $A L T$ and APTT were statistically significant with maternal deaths in comparison to mothers who survived. Keywords: PIH, Uric acid, LDH, AST

\section{Introduction}

Maternal mortality still remains very high in developing countries including India. Maternal Mortality Ratio (MMR) in India is 200 per 1 lakh live births. Medical conditions like eclampsia, ante-partum hemorrhage, post-partum hemorrhage all have increased MMR [1]. So the lifetime risk of maternal death is 1 in 170 livebirths. In India on an average one maternal death occurs every 10 minutes (UN report). Hypertension in pregnancy $(16 \%)$ is one of the top five causes of maternal mortality. Hypertensive disorders of pregnancy represent a group of conditions associated with high blood pressure during pregnancy proteinuria and in some cases convulsions. The most serious consequences for the mother and baby are result of pre-eclampsia and eclampsia $[2,3,4]$.

Pre-eclampsia produces potentially lethal complications including placental abruption, disseminated intravascular coagulation, intracranial haemorrhage, hepatic failure, acute renal failure and cardiovascular collapse. Preeclampsia is still regarded as a disease of theories and its etiology has remained poorly understood. However, endothelial dysfunction has been considered to play a central role in the pathophysiology of preeclampsia [5]. The analysis of a combination of biochemical markers particularly markers related to vascular dysfunction such as increased uric acid, LDH, AST concentration may enrich the ability to predict and prevent $\mathrm{PE}$ in near future [6,7]. Therefore the present study was designed to assess the association of different biochemical parameters like uric acid, LDH, AST, ALT, prothrombin time and APTT with maternal outcomes in PIH cases.

\section{Materials And Methods}

Study setting, study type: This prospective study was carried out in Obstetrics and Gynecology department of Shree Krishna Hospital attached to Pramukhswami Medical College, Karamsad, Gujarat, India.

Study participants \& study period: All pregnant woman admitted between January 2006- March 2008 in the hospital were examined. Blood pressure was measured by mercury sphygmomanometer in reclining position in right brachial artery. Three readings were taken at 10 minutes interval. Participants having average systolic blood pressure $\geq 140 \mathrm{~mm} \mathrm{hg}$ and/or diastolic blood pressure $\geq 90 \mathrm{~mm} \mathrm{Hg}$ were included in the study. Exclusion criteria: Patients with history of hyperuricemia, diabetes, renal diseases, cardiovascular illness, and symptomatic infectious diseases were excluded.

Sample size and sampling: Purposively out of 2237 of total pregnant women admitted in the respected hospital in the defined study period, a total of 328 Participants having average systolic blood pressure $\geq 140 \mathrm{~mm} \mathrm{hg}$ and/or diastolic blood pressure $\geq 90 \mathrm{~mm} \mathrm{Hg}$ or chronic hypertension were included in the present study.

Definitions ${ }^{8}$ : Gestational hypertension is hypertension presenting after 20 weeks without significant proteinuria. Pre-eclampsia is hypertension presenting after 20 weeks with significant proteinuria. Severe pre-eclampsia is pre-eclampsia with severe hypertension and/or with symptoms, and/or biochemical and/or haematological impairment. Eclampsia is a convulsive condition associated with pre-eclampsia. Chronic hypertension is 
hypertension that is present at the booking visit or before 20 weeks or if the woman is already taking antihypertensive medication when referred to maternity services. It can be primary or secondary in etiology. HELLP syndrome is haemolysis, elevated liver enzymes and low platelet count.

Data collection: After enrollment participants were grouped into mild PIH, severe PIH, eclampsia and chronic hypertension. Informed consent was taken from all the participants. The history of all participants was taken. Blood samples of participants were taken from right or left cubital vein and collected in plain and citrate tubes. Prothrombin (PT) and activated partial thromboplastin test (APTT) was performed by turbidometry method $[9,10]$. Aspartate transaminase (AST) and Alanine transaminase (ALT) was measured by Ultra-violet kinetic method [11]. Uric acid was measured by modified Trinder's test [12] and lactate dehydrogenase (LDH) was measured by UV kinetic IFCC [13] method. Participants were observed throughout pregnancy and maternal outcome was observed. This study was approved by the institutional ethical committee.

Study variables: Predictor variables were ALT, AST, PT, APTT, LDH and Uric acid. Outcome variables were maternal complications or maternal death.

Statistical Analysis: The data were cleaned, validated and analyzed with the help of Epi info 7. We used unpaired ' $t$ ' test for comparing the mean level of uric acid, LDH, AST, ALT, PT, APTT with maternal outcome. $\mathrm{p}$ value $<0.05$ was considered statistically significant.

\section{Results \& Discussion}

Table 1: Socio-demographic characteristics of the participants $(n=328)$

\begin{tabular}{|c|c|}
\hline Age distribution & \\
\hline$<20 \mathrm{yrs}$ & $52(15.8 \%)$ \\
\hline $20-25$ yrs & $164(50 \%)$ \\
\hline $26-35 \mathrm{yrs}$ & $103(31.4 \%)$ \\
\hline$>35 \mathrm{yrs}$ & $09(2.7 \%)$ \\
\hline \multicolumn{2}{|l|}{ Type of Admission } \\
\hline Emergency & $272(82.9 \%)$ \\
\hline Booked & $56(17.1 \%)$ \\
\hline \multicolumn{2}{|l|}{ Education level } \\
\hline Illiterate & $186(56.7 \%)$ \\
\hline Primary & $88(26.8 \%)$ \\
\hline Secondary & $28(8.5 \%)$ \\
\hline Graduate & $26(7.9 \%)$ \\
\hline \multicolumn{2}{|l|}{ Ante natal visits } \\
\hline Not taken & $200(60.9 \%)$ \\
\hline Irregularly taken & $55(16.7 \%)$ \\
\hline Regularly taken & $73(22.2 \%)$ \\
\hline \multicolumn{2}{|l|}{ Residence } \\
\hline Rural & $281(85.6 \%)$ \\
\hline Urban & $47(14.3 \%)$ \\
\hline \multicolumn{2}{|l|}{ Socioeconomic status } \\
\hline Low SE & $271(82.6 \%)$ \\
\hline Middle SE & $54(16.4 \%)$ \\
\hline High SE & $3(0.91 \%)$ \\
\hline \multicolumn{2}{|l|}{ Gravida status } \\
\hline Primigravida & $165(50.3 \%)$ \\
\hline $2^{\text {nd }}$ gravida & $74(22.5 \%)$ \\
\hline $3^{\text {rd }}$ gravida & $47(14.3 \%)$ \\
\hline $4^{\text {th }}$ gravida & $29(8.8 \%)$ \\
\hline $5^{\text {th }}$ gravida & $13(3.9 \%)$ \\
\hline
\end{tabular}

Incidence of PIH in this study was $14.6 \%$. Total number of deliveries in this study was 2237 out of which 328 were PIH cases. There were 117 (5.2\%) cases with mild PIH, 136(6.0\%) with severe PIH, 67(2.9\%) with eclampsia and $8(0.35 \%)$ with chronic hypertension. Maternal deaths occurred in 9 PIH cases. MMR in this study was 4.5/1000 livebirths. Among them one had mild PIH - mortality 2/115 (1.74\%), 4 had severe PIH mortality 4/132 (3.0\%) and 3 had eclampsia - mortality 3/ 64 (4.68\%). (Table 2)

Table 2: Maternal death/survival in present study $(\mathrm{n}=328)$ 
Maternal outcome in relation to Biochemical parameters in Hypertensive disorders in Pregnancy

\begin{tabular}{|c|c|c|c|c|c|}
\hline $\begin{array}{l}\text { Death/Survival of } \\
\text { mother }\end{array}$ & Mild PIH* & Severe PIH* & Eclampsia & Chronic HT* & Total \\
\hline Survived & $\begin{array}{l}115 \\
(35.0 \%)\end{array}$ & $\begin{array}{l}132 \\
(40.2 \%)\end{array}$ & $\begin{array}{l}64 \\
(19.5 \%)\end{array}$ & $\begin{array}{l}8 \\
(2.43 \%)\end{array}$ & $\begin{array}{l}319 \\
(97.25 \%)\end{array}$ \\
\hline Maternal deaths & $\begin{array}{l}2 \\
(1.74 \%)\end{array}$ & $\begin{array}{l}4 \\
(3.0 \%)\end{array}$ & $\begin{array}{l}3 \\
(4.64 \%)\end{array}$ & $\begin{array}{l}0 \\
0 \\
(0.0 \%)\end{array}$ & $\begin{array}{l}9 \\
(2.74 \%)\end{array}$ \\
\hline Total & 117 & 136 & 67 & 8 & 328 \\
\hline
\end{tabular}

*(PIH- Pregnancy Induced Hypertension, HT- Hypertension)

Main cause of maternal death was cardiac arrest (34\%) and 22\% Eclampsia and pulmonary edema as well. (Chart A)

Chart A: Causes of maternal death in present study (n=9)

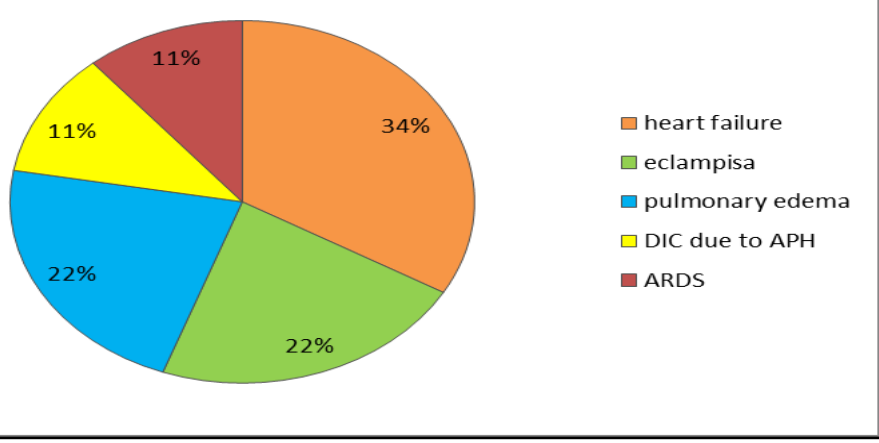

Isolated Thrombocytopenia (15.5\%) was the most common maternal complication followed by pulmonary edema $(8.8 \%)$ seen in present study. (Table 3 )

Table 3: Maternal complications in present study $(n=166)$

\begin{tabular}{|l|l|}
\hline Maternal complications & Total \\
\hline Isolated Thrombocytopenia & $51(15.5 \%)$ \\
\hline Pulmonary edema & $29(8.8 \%)$ \\
\hline Antepartum Hemorrhage (APH) & $23(7.0 \%)$ \\
\hline Jaundice & $17(5.18 \%)$ \\
\hline Cardiorespiratory arrest & $7(2.1 \%)$ \\
\hline Disseminated Intravascular Coagulation(DIC) & $10(3.0 \%)$ \\
\hline HELLP & $13(3.9 \%)$ \\
\hline Renal failure & $9(2.7 \%)$ \\
\hline Post partum Hemorrhage (PPH) & $4(1.2 \%)$ \\
\hline Acute Respiratory Distress Syndrome(ARDS) & $3(0.9 \%)$ \\
\hline
\end{tabular}

Table 4:-Comparison of biochemical parameters in relation to maternal deaths $(n=328)$

\begin{tabular}{|l|l|l|l|}
\hline Parameters & $\begin{array}{l}\text { Deaths } \\
\text { Mean } \pm \text { SD }\end{array}$ & $\begin{array}{l}\text { Live } \\
\text { Mean } \pm \text { SD }\end{array}$ & p-Value \\
\hline ALT & $163.78 \pm 382.7$ & $41.47 \pm 65.23$ & $<0.0001^{*}$ \\
\hline AST & $354.78 \pm 900.18$ & $60.53 \pm 133.17$ & $<0.0001^{*}$ \\
\hline Uric acid & $9.20 \pm 3.032$ & $6.33 \pm 2.159$ & $0.0002^{*}$ \\
\hline LDH & $674.44 \pm 266.37$ & $490.20 \pm 236.32$ & $0.0222^{*}$ \\
\hline APTT & $42.67 \pm 29.45$ & $30.71 \pm 7.47$ & $<0.0001^{*}$ \\
\hline PT & $12.78 \pm 1.20$ & $13.16 \pm 1.03$ & 0.277 \\
\hline
\end{tabular}

$* \mathrm{p}<0.05$ statistically significant

From the Table no 4 it's obvious that there is a statistically significant relation between elevated serum ALT, AST, APTT, uric acid, LDH and maternal deaths. Prothrombin Time was not found to be significant in relation to maternal death

All the 9 maternal deaths were admitted during emergency, 8(88.8\%) came from rural areas; they belonged to low socioeconomic class and had not taken antenatal care. $7(77.7 \%)$ were illiterate, one had taken primary education and one was a graduate. 7 of the maternal deaths were primigravidas, 7 (77.7\%) were from the 20-25yrs age group and 5(55.5\%) cases were referred from outside hospital, this may be due to the fact that our institute is a well equipped and established tertiary care center located in a rural area, receiving a large number of high risk patients from surrounding locations. 
Out of the 9 deaths 3 patients died in antepartum period, 3 in intrapartum period and 3 postpartum period. Out of these, 6 patients died undelivered, 2 delivered by vaginal route and one underwent LSCS.

There are several potential origins for raised uric acid concentration in preeclampsia, usually it's secondary to altered renal function, increased tissue breakdown, increased oxidative stress and increased activity of xanthine oxidase [14]. In normal pregnancy due to plasma volume expansion Serum uric acid levels are between $2-5 \mathrm{mg} / \mathrm{dl}$. Greater then $5.5 \mathrm{mg} / \mathrm{dl}$ is consistent with preeclampsia and values exceeding $6.0 \mathrm{mg} / \mathrm{dl}$ suggest more serious disease [15]. Patient with both hyperuricemia and hypertension in the second half of pregnancy is more likely to have preeclampsia even in the absence of proteinuria. Uric acid with $>6 \mathrm{mg} / \mathrm{dl}$ showed 21.5 fold risk of maternal mortality than in women with $<6 \mathrm{mg} / \mathrm{dl}$ uric acid levels. Hyperuricemia patients with severe preeclampsia is a strong risk factor for several perinatal complications and increase the risk for intra uterine death by 30.4 times, cesarean section by 6 folds, maternal mortality by 21.5 times, IUGR by 6 folds and eclampsia by 14.3 fold in those with a uric acid level $>6 \mathrm{mg} / \mathrm{dl}$ as compared to a level $<6 \mathrm{mg} / \mathrm{dl}$ [16].

Elevated uric acid levels had nearly seven fold increased risk of premature delivery than preeclamptic women whose uric acid levels were normal. One unit increase in uric acid the odds of preterm births increased 2-3 times [17] These finding are in agreement to our findings showing $100 \%$ maternal deaths, $77.6 \%$ with eclampsia, and $26.8 \%$ with preterm delivery in hypertensive mothers with uric acid levels $>6.0 \mathrm{mg} / \mathrm{dl}$ (Table 5).

Table 5:- Pregnancy Outcome in relation to biochemical parameters

\begin{tabular}{|c|l|l|l|l|}
\hline & URIC ACID & LDH & ALT \\
$\mathbf{2}$ & $\mathbf{6 . 0}$ & $\mathbf{6 0 0}$ & $\begin{array}{l}\text { AST } \\
\mathbf{7 2}\end{array}$ \\
\hline $\begin{array}{c}\text { Maternal deaths } \\
(9)\end{array}$ & 9 & 7 & 2 & 4 \\
$(100 \%)$ & $(77.7 \%)$ & $(22.2 \%)$ & $(44.4 \%)$ \\
\hline $\begin{array}{c}\text { Preterm delivery } \\
(194)\end{array}$ & 52 & 34 & 21 & 28 \\
& $(26.8 \%)$ & $(17.5 \%)$ & $(10.8 \%)$ & $(14.4 \%)$ \\
\hline $\begin{array}{c}\text { Eclampsia } \\
(67)\end{array}$ & 52 & 31 & 11 & 13 \\
& $(77.6 \%)$ & $(46.2 \%)$ & $(16.4 \%)$ & $(19.4 \%)$ \\
\hline
\end{tabular}

Several studies have demonstrated a correlation between elevated maternal serum uric acid levels and adverse maternal outcome, to be useful test to predict maternal complications in the management of women with preeclampsia $[18,19,20]$. Elevated level of serum LDH and AST indicates tissue damage related to endothelial vascular damage and is the main cause of the occurrence of preeclampsia [21,22]. Qublan HS showed 92\% patients had multi-organ dysfunction in severe preeclamptic women having LDH>800 IU/l. Severely preeclamptic women with LDH >800 IU/l showed significant increase in terms of eclampsia, abruptio placenta, intracranial hemorrhage, HELLP syndrome, acute renal failure, disseminated intravascular coagulation, and pulmonary edema compared with women who had lower levels $(\mathrm{p}<0.001)$ [22]. In this study hypertensive mothers with LDH levels > 600IU/l were seen in $77.7 \%$ maternal deaths, out of these three mothers $(42.8 \%)$ had LDH > $800 \mathrm{IU} / 1$. Serum LDH > 600IU/l was also observed in hypertensive mothers having $17.5 \%$ preterm deliveries and $46.2 \%$ were eclamptic (Table 5). Higher levels of serum LDH and AST are very useful markers to identify the occurrence of the complications of preeclampsia in early pregnancy which may reduce the risk of occurrence of disease [7,23]. Maternal complications were seen in $37 \%$ preeclamptic women with abnormal liver function tests $(\mathrm{P}<0.01)$ than in preeclamptic women with normal LFT [24]. APTT is probably a practical and cost-effective way to screen for consumptive coagulopathy in preeclampsia [25]. Bad laboratory results and the intensification of clinical signs with multi-organ dysfunction are indications for termination of pregnancy [26].

\section{Conclusion:}

Preeclampsia is a multisystem disorder, characterized by vascular endothelial dysfunction. We found a statistically significant difference between serum uric acid, LDH, AST, ALT, and APTT with maternal death in PIH cases. So higher levels of these parameters can be very useful markers to identify the occurrence of the complications of preeclampsia in early pregnancy and help in the management of the women with preeclampsia.

\section{References:}

[1]. Datta D, Datta PP. Maternal Mortality In India: Problems and Strategies. Asian Journal of Medical Research. 2013; 2(1): 33-35

[2]. Sibai BM, Gordon T, Thom E. Risk factors for preeclampsia in healthy nulliparous women: a prospective multicenter study. The National Institute of Child Health and Human Development Network of Maternal - Fetal Medicine Units. Am J Obstet Gynecol. 1995; 172(2): 642-48.

[3]. LoJo, Mission JF, Caughey AS, Hypertensive disease of pregnancy and maternal mortality. Curr Opin. Obstet Gynecol. 2013 April; 25(2): 124-32.

[4]. Ghulmiyyah L, Sibai B. Semin Perinatol.Maternal mortality from preeclampsia/ Eclampsia. 2012 Feb; 36(1); 56-9.

[5]. Dekker GA, Sibai BM. Etiology and Pathogenesis of PE: Current concepts. AM J Obstet Gynecol. 1998; 179(5):1359-75.

[6]. Matsubara K, Matsubara Y, Masaharu ITO. The utility of vascular dysfunction studies in the prediction and prevention of preeclampsia: A historical review. Vascular disease prevention. 2009; 6:163-69.

[7]. R.Aziz, Tabassum M. Preeclampsia \& Cardiac enzymes is there any relation.. 2010.www.crc.mui.ac.ir/arya/1655/pdf 
[8]. NICE clinical guideline 107. Hypertension in pregnancy: The management of hypertensive disorders during pregnancy [Internet] [Issued: August 2010; last modified: January 2011; Cited 2014 January 16]. Available from: www.nice.org.uk/nicemedia/live/13098/50418/50418.pdf

[9]. Biggs, R.: Human Blood Coagulation, Haemostasis and Thrombosis.” 2nd edi. Blackwell Scientific Publications, London .1976

[10]. Talke, H. and Schubert, G.E: Enzymatic urea determination in the blood and serum in the Warburg optical test. Klin Wochenschr.1965; 43: 174-175

[11]. Trinder, P.J. Clin Pathol.1949; 22: 246-250

[12]. Bauer, P.J. Anal Biochem.1981; 110(1): 61-72

[13]. Kansaria, J.J. and Parulekar, S.V. Bombay Hospital J.2008; 50(1): 19-25

[14]. Johnson RJ, Kang DH, Feig D, Kivligh S, Kanellis J, Watanabe S, Tuttle KR, Rodriguez IB, Herrera AJ, Mazzali M. Is there a pathogenic role of uric acid in hypertension and cardiovascular and renal disease? Hypertension. 2003; 41:1183-90.

[15]. Cnossen JS, de Ruyter-Hanhijärvi H, van der Post JA, Mol BW, Khan KS and Riet G. "Accuracy of serum uric acid determination in predicting pre-eclampsia: a systematic review". Acta Obstet Gynecol Scand. 2006; 85(5):519-22

[16]. Yassare F."Hyperuricemia and Perinatal Outcomes in Patients with Severe Preeclampsia". Iran J Med Science 2003; 28(4): 198199.

[17]. Robert JM, Bodnar LM, Lain KY, Hubel CA, Markovic N, Ness RB, Powers RB. Uric acid Is as Important as Proteinuria in Identifying Fetal Risk in Women With Gestational Hypertension. Hypertension 2005;46:1263-1269

[18]. Lancet M, Fisher IL. The value of blood uric acid in toxemia of pregnancy. J Obstet Gynecol. 1956; 63:116-19.

[19]. Razia Sultana, Selina A, Nasima S, Faziul Ksrim SM, Farhana A. Association of serum uric acid with preeclampsia: A case control study. Delta Med Col J. 2013; 1(2)46-50

[20]. Hawkins TL, Roberts LM, Brown MA Plasma Uric acid remains a marker of poor outcome in hypertensive pregnancy: a retrospective cohort study. BJOG. 2012; 119(4): 484-92.

[21]. Purnima Dey S, Jonal S. Evaluation of serum LDH and gamma glutamyl transferase in preeclamptic pregnancy in third trimester. Int J Res Med Sci .2013:1(4) 365-368

[22]. Qublan HS, Ammarin V, Bataineh O, Al-Shraideh Z, Tahat Y, Awamleh I, Khreisat B, Nussair B and Amarin ZO. "Lactic dehydrogenase as a biochemical marker of adverse pregnancy outcome in severe pre-eclampsia”. Med Sci Monit, 2005; 11(8): 393-397.

[23]. SP Jaiswal, Amrit G, Mohan S. Lactate dehydrogenase: A Biochemical marker for preeclampsia -eclampsia. J Obstet Gynaecol India. 2011; 61(6):645-648.

[24]. Girling JC. "Liver function tests in pre-eclampsia: importance of comparison with a reference range derived for normal pregnancy". British J Obstetrics \& Gynaecology.1997; 104(2): 246-250.

[25]. Metz J, Cincotta R, Francis M, Derosa L, Balloch A. Screening for consumptive coagulopathy in preeclampsia. IJ Obstet Gynaecol. 1994; 46: 3-9

[26]. Dusica Maksmilijan Kocijancic, snenzana P, Darkkoplecan. Correlation of biochemical parameters \& neonatal outcome in patients with gestational hypertension. Clinical \& experimental hypertension. 2013; 35(1): 6-10. 